\title{
ANP and BNP plasma levels in patients with rheumatic mitral stenosis after percutaneous balloon mitral valvuloplasty
}

\author{
Łukasz Mazurkiewicz' ${ }^{1}$ Witold Rużyłło², Zbigniew Chmielak², Ewa Opalińska-Ciszek², Jadwiga Janas², \\ Piotr Hoffman ${ }^{4}$, Tomasz Hryniewiecki ${ }^{5}$, Jacek Grzybowski ${ }^{6}$ \\ ${ }^{1}$ Department of Cardiomyopathies, CMR Unit, Institute of Cardiology, Warsaw, Poland \\ ${ }^{2}$ Institute of Cardiology, Warsaw, Poland \\ ${ }^{3}$ Department of Cardiology and Interventional Angiology, Institute of Cardiology, Warsaw, Poland \\ ${ }^{4}$ Department of Congenital Cardiac Defects, Institute of Cardiology, Warsaw, Poland \\ ${ }^{5}$ Department of Acquired Cardiac Defects, Institute of Cardiology, Warsaw, Poland \\ ${ }^{6}$ Department of Cardiomyopathies, Institute of Cardiology, Warsaw, Poland
}

Adv Interv Cardiol 2017; 13, 1 (47): 18-25

DOI: https://doi.org/10.5114/aic.2017.66182

\begin{abstract}
A bstract
Introduction: Atrial (ANP) and B-type (BNP) natriuretic peptides are hormones secreted by the heart as a response to volume expansion and pressure overload.

Aim: To assess the changes of ANP and BNP after percutaneous balloon mitral valvuloplasty (PBMV) and to investigate factors associated with endpoints.

Material and methods: The study included 96 patients (90.7\% females, age $51.6 \pm 12.2$ years) with rheumatic mitral valve stenosis (mitral valve area (MVA) 1.18 (1.01-1.33) cm², mean mitral gradient (MMG) 8.2 (7.1-9.2) mm Hg, NYHA 2.09 (1.9-2.5)). Patients were followed up for 29.1 months for the search of endpoints.

Results: The PBMV was successful in all cases. After the procedure MVA increased $\left(1.18-1.78 \mathrm{~cm}^{2}, p<0.01\right)$ and pulmonary capillary wedge pressure (PCWP) decreased $(29.8-21.8 \mathrm{~mm} \mathrm{Hg}, p<0.01)$. Concentration of ANP significantly rose 30 min after the PBMV (79.2 vs. $134.2 \mathrm{pg} / \mathrm{ml}, p=0.012)$ and dropped significantly after $24 \mathrm{~h}(134.2 \mathrm{vs} .70 .4 \mathrm{pg} / \mathrm{ml}, p=0.01)$. Furthermore, after 36 months concentration of ANP did not differ from the baseline value $(p=$ NS). BNP concentration at day 1 was lower than at baseline ( 94.5 vs. $80.2 \mathrm{pg} / \mathrm{ml}, p=0.032$ ). Moreover, during the follow-up period BNP continued to fall at all time points. In univariate analysis parameters associated with endpoint occurrence were baseline PAP $(p=0.023)$, baseline PCWP $(p=0.022)$, baseline NYHA $(p=0.041)$ and increase in 6-minute walk test $(6 \mathrm{MWT})(p=0.043)$. In multivariate analysis the only factor associated with endpoint occurrence was baseline NYHA ( $\mathrm{HR}=1.52,95 \% \mathrm{Cl}:-1.3-1.91, p=0.022)$.

Conclusions: Patients with MS had increased levels of both BNP and ANP. Baseline NYHA class was found to be associated with outcomes after the procedure.
\end{abstract}

Key words: mitral stenosis, percutaneous mitral valvuloplasty, neurohormones.

\section{Introduction}

Rheumatic mitral stenosis (MS) is a valvular heart disease associated with slow clinical course [1-3] usually as a result of rheumatic fever [4-6]. Its pathophysiological pattern consists of the degeneration of the mitral apparatus, narrowing of the area of the mitral orifice, enlarging of the left atrium and development of pulmonary hypertension [7-10]. The main clinical symptoms may include heart failure and arrhythmias [11-13]. The first invasive therapeutic option, which should be considered in patients with mitral stenosis with favorable valve morphology, is percutaneous balloon mitral valvuloplasty (PBMV) $[14,15]$. The PBMV results in decreasing atrial and pulmonary pressure with increasing left ventricular preload [16-18].

Human natriuretic peptides play an important role as a marker of the severity of heart failure $[19,20]$. Previ-

\section{Corresponding author:}

Lukasz Mazurkiewicz MD, PhD, Department of Cardiomyopathies, CMR Unit, Institute of Cardiology, 42 Alpejska St, 04-628 Warsaw, Poland, phone: +48 501717 527, e-mail: Imazurkiewicz@ikard.pl

Received: 13.04.2016, accepted: 19.08.2016. 
ous studies confirmed the diagnostic and prognostic role in heart failure in the course of either primary diseases or ischemic injury of the myocardium [21]. It is believed that, in the human heart, atrial natriuretic peptide (ANP) is secreted in atria and brain natriuretic peptide (BNP) in ventricles, as a result of the heart walls stretching caused by volume overload [22]. ANP and BNP have similar activities - natriuresis, diuresis and vasodilatation [23].

An increase in both ANP and BNP in patients with MS has been reported in previous studies [24, 25]. Many papers describe the neurohormonal changes as consequences of hemodynamic alterations after PBMV [26, 27]. Those reports are based on the results collected in the first few days after the procedure. To date we are not aware of any publications that include long-term neurohormonal, echocardiographic and functional follow-up in patients after PBMV. This study was designed to determine the magnitude, direction and significance of changes in neurohormonal activation during 36 months after the PBMV procedure.

\section{Aim}

The aim of the study were: to determine the changes of concentrations of ANP and BNP during 36-month follow-up, to correlate the changes of neurohormonal concentrations with clinical, echocardiographic and functional status and to find factors which might be associated with endpoint occurrence.

\section{Material and methods}

The study group consisted of 96 consecutive, prospectively evaluated patients with symptomatic MS who underwent a PBMV procedure in our centre.

\section{Inclusion criteria}

The inclusion criteria were:

- significant mitral stenosis defined by area of mitral orifice $<1.5 \mathrm{~cm}^{2}$,

- symptoms of heart failure.

\section{Exclusion criteria}

Exclusion criteria were:

- more than mild mitral regurgitation,

- severe mitral valve or mitral apparatus calcifications,

- thrombus in heart chambers,

- absence of commissural fusion,

- severe concomitant aortic valve disease or severe combined tricuspid stenosis and regurgitation,

- concomitant coronary artery disease requiring bypass surgery,

- other previous cardiac diseases or events, such as other than mitral significant valve disease, previous myocardial infarction, cardiomyopathy, previous percutaneous transluminal coronary angioplasty, previ- ous coronary artery bypass grafting, history of pulmonary embolism, aortic aneurysm, pacemaker or ICD/ CRT implantation.

\section{Clinical assessment}

All patients underwent standard physical examination including 12-lead electrocardiogram, 6-minute walk test $(6 \mathrm{MWT})$ and blood sample collection for laboratory analysis at baseline.

After discharge from hospital, patients were invited to outpatient visits, which took place 30 days, 12 months, 24 months and 36 months after the PBMV. During those visits patients underwent clinical, echocardiographic, functional and neurohormonal evaluation.

A control group of healthy volunteers ( $n=22 ; 5$ males, mean age: $57.2 \pm 7.1$ years) with no significant medical history, and normal physical examination and 12-lead ECG results served as controls for neurohormonal comparisons.

The patients were followed up for the first occurrence of endpoints, which included death, mitral valve replacement (MVR) or repeated PBMV.

\section{Neurohormonal evaluation}

Blood samples were collected by venipuncture (except samples collected $30 \mathrm{~min}$ after the PBMV which were obtained from a sheath inserted into the femoral vein). The analysis was done using radioimmunoassay (Roche Diagnostic). The schedule of the blood sampling was as follows: 1 day before PBMV and then $30 \mathrm{~min}$, 24 h, 30 days, 12 months, 24 months, and 36 months after the PBMV.

Controls had only one blood collection for neurohormonal analysis.

\section{Echocardiographic measurements}

Echocardiographic assessment was performed using the GE Vingmed System 1 day before PBMV, $24 \mathrm{~h}$, 30 days, 12 months, 24 months and 36 months after the PBMV.

M-mode, two-dimensional, and Doppler echocardiograms were obtained in all subjects in the left lateral decubitus position. Left ventricular and left atrial dimensions were measured in the parasternal long axis view. Rheumatic valvular disease was diagnosed based on features such as thickening of valve leaflets and chordal apparatus, restricted leaflet separation, diastolic doming of the anterior mitral leaflet, commissural fusion or M-mode detection of diminished mitral E-F slope, and upward movement of posterior mitral leaflet in early diastole. The degree of the stenosis was quantified by planimetry in two-dimensional images, by Doppler measurement of transvalvular gradients and by the estimation of valve area (MVA) by the pressure half-time method. Also peak mitral gradient (PMG) and mean mi- 
tral gradient (MMG) were obtained. Doppler methods were used in the assessment of the severity of valvular regurgitation. Transoesophageal echo was performed for thrombus exclusion before PBMV.

Measurements represent an average of three beats for patients in sinus rhythm and 10 beats for patients in atrial fibrillation [28-30].

\section{Invasive procedure}

The PBMV procedure was performed using the Inoue technique and is described elsewhere [31]. Immediately before and after the invasive therapeutic procedure right heart catheterization was performed and pressures from the pulmonary artery (PAP), pulmonary capillaries (PCWP), left (LAP) and right (RAP) atrium and left ventricle as well as cardiac output (CO) by the Fick method were obtained.

\section{Statistical analysis}

Qualitative variables were analyzed by descriptive statistics. Frequency distributions were compiled and

Table I. Baseline clinical characteristics

\begin{tabular}{|c|c|}
\hline Parameter & Result \\
\hline Male sex, $n(\%)$ & $9(9.3)$ \\
\hline Age [years] & $51.6 \pm 12.2$ \\
\hline Sinus rhythm, $n$ (\%) & $57(59.3)$ \\
\hline NYHA & $2.09(1.9-2.5)$ \\
\hline $\operatorname{RAP}[\mathrm{mm} \mathrm{Hg}]$ & $47.3(44.7-49.3)$ \\
\hline $\operatorname{LAP}[\mathrm{mm} \mathrm{Hg}]$ & $31.2(24.1-38.8)$ \\
\hline $\mathrm{PCWP}[\mathrm{mm} \mathrm{Hg}]$ & $29.8(23.1-36.5)$ \\
\hline PMG [mm Hg] & $17.1(14.1-18.8)$ \\
\hline $\mathrm{MMG}[\mathrm{mm} \mathrm{Hg}]$ & $8.2(7.1-9.2)$ \\
\hline $\mathrm{MVA}\left[\mathrm{cm}^{2}\right]$ & $1.18(1.01-1.33)$ \\
\hline $\mathrm{CO}[\mathrm{l} / \mathrm{min}]$ & $5.2(4.9-5.6)$ \\
\hline LVEDD [mm] & $49.3(40.1-55.2)$ \\
\hline LVESD [mm] & $31.1(25.2-37.7)$ \\
\hline $\operatorname{LVEF}[\mathrm{mm}]$ & $63.4(55.2-69.4)$ \\
\hline RVEDD [mm] & $37.5(31.8-44.5)$ \\
\hline TAPSE $[\mathrm{mm}]$ & $21.1(19.1-25.7)$ \\
\hline Wilkins score & 6.4 \\
\hline $6 \mathrm{MWT}[\mathrm{m}]$ & $422(320-560)$ \\
\hline
\end{tabular}

RAP - right atrial pressure, $L A P$ - left atrial pressure, $P C W P$ - pulmonary capillary wedge pressure, $P M G$ - peak mitral gradient, $M M G$ - mean mitral gradient, MVA - mitral valve area, CO - cardiac output, LVEDD - left ventricle end diastol ic diameter, LVESD - left ventricle end systolic diameter, LVEF - left ventricle ejection fraction, RVEDD - right ventricle end diastolic diameter, TAPSE - tricuspid annular plane systolic excursion, 6MWT-six-minute walk test. calculated using the mean and standard deviations of continuous variables or median and interquartile range, as appropriate. The choice of statistical test to be used (parametric or nonparametric) in assessing variables came after analysis of the variables of normal distribution using the Kolmogorov-Smirnov and Shapiro-Wilk tests. To estimate the parameters determining neurohormone level changes, the paired $t$-test was used. Correlations were assessed using Pearson's test. The duration of follow-up was computed using the index date to the date of the first endpoint or last clinical follow-up. Cox proportional hazards analyses were used to assess the relationship between the parameters and endpoints. The following parameters were entered into univariate Cox regression analysis: baseline PAP, baseline PCWP, baseline NYHA class, baseline result of 6-minute walk test, PMG at baseline and at the end of the study, MGM at baseline and at the end of the study, MVA at baseline and at the end of the study, BNP and ANP concentrations at baseline and at the end of the study. All significant univariate predictors of endpoints were proposed for inclusion in multivariate backward stepwise Cox models. Hazard ratios (HR) are expressed as mean and $95 \% \mathrm{Cl}$. Values of $p<0.05$ were considered as statistically significant.

\section{Results}

Patients with mitral stenosis had significantly higher levels of both ANP (79.2 (65.2-143.1) vs. 4.4 (1.4-9.1) $\mathrm{pg} / \mathrm{ml}, p<0.001)$ and BNP (94.5 (81.2-132.1) vs. 9.1 (2.4-15.2) pg/ml, $p<0.001$ ) when compared to healthy controls. Baseline clinical characteristics are presented in Table I. We found no differences in neurohormone concentrations between patients with sinus rhythm and atrial fibrillation (AF). Patients with AF had a larger left atrium (Table II).

\section{Immediate result}

The PBMV was successful in all cases. Changes in hemodynamic and echocardiographic parameters immediately after PBMV are shown in Table III.

\section{Follow-up}

Mean follow-up time was 29.1 months.

At the end of the follow-up period MVA (1.18 (1.01$1.33)$ vs. $\left.1.66(1.22-1.78) \mathrm{cm}^{2}, p=0.011\right)$ was still significantly higher than at baseline with the drop in PMG (17.1 (14.1-18.8) vs. $11.6(9.91-11.2) \mathrm{mm} \mathrm{Hg}, p=0.031)$ and in MMG (8.2 (7.1-9.2) vs. 5.9 (6.1-8.4) $\mathrm{mm} \mathrm{Hg}, p=$ $0.023)$. Also functional status of the patients was better than baseline - 6-minute walking distance increased (422 (320-560) vs. 462 (430-590) $\mathrm{m}, p=0.21$ ), NYHA (2.09 (1.9-2.5) vs. $1.8(1.7-2.3), p=0.043)$.

During the follow-up, 22 (22.9\%) patients had endpoints: 4 (4.1\%) patients died (all patient died due to heart failure), 10 (10.4\%) patients had MVR and 8 (8.2\%) 
Table II. Comparison of clinical characteristics of patients with sinus rhythm and atrial fibrillation

\begin{tabular}{|c|c|c|c|}
\hline Parameter & Patients with SR $(n=57)$ & Patients with AF $(n=39)$ & $P$-value \\
\hline Male sex, $n(\%)$ & $6(10.5)$ & $3(8.1)$ & NS \\
\hline Age [years] & $51.8 \pm 11.9$ & $52.7 \pm 12.4$ & NS \\
\hline NYHA & $2.08(1.9-2.5)$ & $2.09(1.8-2.4)$ & NS \\
\hline $\operatorname{RAP}[\mathrm{mm} \mathrm{Hg}]$ & $45.2(43.1-48.1)$ & $48.3(46.7-50.5)$ & NS \\
\hline $\operatorname{LAP}[\mathrm{mm} \mathrm{Hg}]$ & $30.1(26.2-36.1)$ & $32.1(25.2-39.5)$ & NS \\
\hline PCWP [mm Hg] & $28.3(25.1-31.4)$ & $29.1(26.1-31.1)$ & NS \\
\hline PMG [mm Hg] & $17.1(14-18.3)$ & $17.7(14.5-19.4)$ & NS \\
\hline $\mathrm{MMG}[\mathrm{mm} \mathrm{Hg}]$ & $7.9(7.1-9.1)$ & $8.2(7.5-9.6)$ & NS \\
\hline $\mathrm{MVA}\left[\mathrm{cm}^{2}\right]$ & $1.20(1.03-1.36)$ & $1.16(1.0-1.3)$ & NS \\
\hline LAA $\left[\mathrm{cm}^{2}\right]$ & $34.1(31.1-42.3)$ & $42.3(35.2-48.7)$ & $<0.01$ \\
\hline $\mathrm{CO}[1 / \mathrm{min}]$ & $5.3(4.8-5.7)$ & $5.1(4.5-5.5)$ & NS \\
\hline LVEDD $[\mathrm{mm}]$ & $48.1(41.2-54.3)$ & $49.3(40.5-55.1)$ & NS \\
\hline $\operatorname{LVESD}[\mathrm{mm}]$ & $30.2(24-36)$ & $32.1(26.3-39.5)$ & NS \\
\hline $\operatorname{LVEF}[\mathrm{mm}]$ & $62.3(55-68)$ & $63.1(54.1-67.4)$ & NS \\
\hline $\operatorname{RVEDD}[\mathrm{mm}]$ & $36(30.4-45.8)$ & $38(31.3-46.5)$ & NS \\
\hline TAPSE $[\mathrm{mm}]$ & $22.5(20.1-26.6)$ & $21.4(19.8-24.2)$ & NS \\
\hline $6 \mathrm{MWT}[\mathrm{m}]$ & $428.3(318.4-565.5)$ & $419.1(303.4-542.8)$ & NS \\
\hline ANP $[\mathrm{pg} / \mathrm{ml}]$ & $73.1(62.9-141.3)$ & $78.1(66.2-149.6)$ & NS \\
\hline $\mathrm{BNP}[\mathrm{pg} / \mathrm{ml}]$ & $91.6(82.2-135.2)$ & $97.2(87.3-139.1)$ & NS \\
\hline
\end{tabular}

$S R$ - sinus rhythm, AF - atrial fibrillation, RAP - right atrial pressure, LAP - left atrial pressure, PCWP - pulmonary capillary wedge pressure, PMG - peak mitral gradient, MMG - mean mitral gradient, MVA - mitral valve area, CO - cardiac output, LVEDD - left ventricle end diastolic diameter, LVESD - left ventricle end systolic diameter, LVEF - left ventricle ejection fraction, RVEDD - right ventricle end diastolic diameter, TAPSE - tricuspid annular plane systolic excursion, 6MWT - six-minute walk test, LAA - left atrium area.

patients had repeated PBMV. Endpoints occurred in 13 (22.8\%) patients who had sinus rhythm at baseline and in $9(23.1 \%)$ subjects with AF at that time ( $p=N S)$.

Among the study subjects 8 (8.3\%) patients had stroke, but an association with AF was not found. On the other hand, 10 (10.4\%) patients had changed heart rhythm from sinus to AF.

\section{Neurohormones}

Concentration of ANP significantly rose 30 min after the PBMV and following that peak dropped significantly to a concentration lower than at baseline after $24 \mathrm{~h}$. Furthermore, during follow-up the concentration of ANP did not differ from the baseline value.

Changes in ANP concentrations in the follow-up period are presented in Figure 1.

Unlike ANP concentration, BNP concentration had no 30-minute peak after the PBMV. However, at day 1 BNP concentration was also significantly lower than at baseline. Moreover, during the follow-up period BNP continued to fall at all successive time points.

Changes in BNP concentrations in the follow-up period are presented in Figure 2.

\section{Correlations}

Higher baseline concentration of ANP was associated with higher LAP $(r=0.452, p=0.013)$, higher PMG $(r=0.329, p=0.021)$, higher MGM $(r=0.341, p=0.034)$,

Table III. Immediate result of PBMV

\begin{tabular}{|c|c|c|}
\hline Parameter & Result & $P$-value \\
\hline $\operatorname{RAP}[\mathrm{mm} \mathrm{Hg}]$ & $\begin{array}{c}47.3(44.7-49.3) \\
\text { vs. } 22.7(21.5-24.1)\end{array}$ & $<0.001$ \\
\hline $\operatorname{LAP}[\mathrm{mm} \mathrm{Hg}]$ & $\begin{array}{c}31.2(24.1-38.8) \\
\text { vs. } 19.5(18.1-21.1)\end{array}$ & $<0.001$ \\
\hline PCWP [mm Hg] & $\begin{array}{c}29.8(21.1-30.5) \\
\text { vs. } 21.8(20.6-22.8)\end{array}$ & $<0.001$ \\
\hline $\mathrm{PMG}$ [mm Hg] & $\begin{array}{c}17.1(14.1-18.8) \\
\text { vs. 10.6 (9.8-11.3) }\end{array}$ & $<0.001$ \\
\hline $\mathrm{MMG}[\mathrm{mm} \mathrm{Hg}]$ & $\begin{array}{c}8.2(7.1-9.2) \\
\text { vs. } 5.1(4.3-5.9)\end{array}$ & $<0.001$ \\
\hline $\operatorname{MVA}\left[\mathrm{cm}^{2}\right]$ & $\begin{array}{c}1.18(1.01-1.33) \\
\text { vs. } 1.78(1.71-1.84)\end{array}$ & $<0.001$ \\
\hline $\mathrm{CO}[\mathrm{l} / \mathrm{min}]$ & $\begin{array}{c}5.2(4.9-5.6) \\
\text { vs. } 5.6(4.9-5.8)\end{array}$ & 0.056 \\
\hline
\end{tabular}

$R A P$ - right atrial pressure, $L A P$ - left atrial pressure, $P C W P$ - pulmonary capillary wedge pressure, $P M G$ - peak mitral gradient, $M M G$ - mean mitral gradient, MVA - mitral valve area, $\mathrm{CO}$ - cardiac output. 


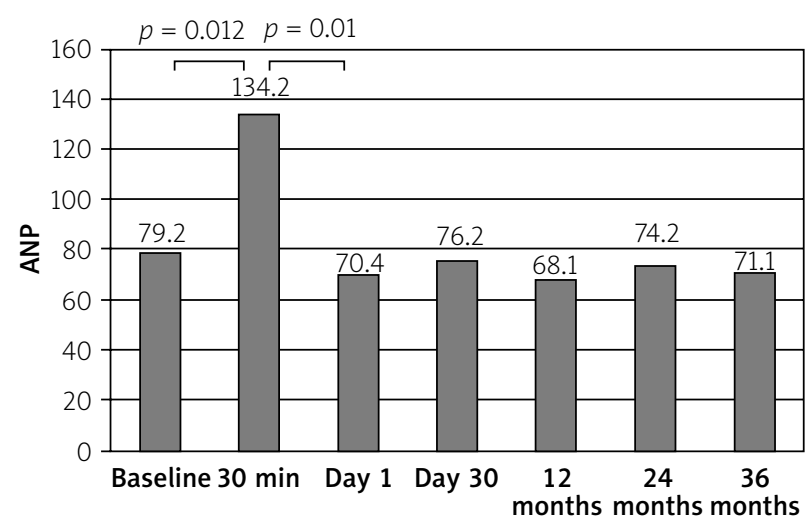

Figure 1. Changes in ANP concentrations during follow-up

Table IV. Prognostic factors in univariate analysis

\begin{tabular}{|c|c|c|c|}
\hline Variable & $\begin{array}{c}\text { Hazard ratio } \\
\text { HR }\end{array}$ & $\begin{array}{l}95 \% \text { confidence } \\
\text { intervals }\end{array}$ & $P$-value \\
\hline Baseline PAP & 2.02 & $1.03-3.92$ & 0.023 \\
\hline Baseline PCWP & 1.16 & $1.02-1.93$ & 0.022 \\
\hline Baseline NYHA & 1.33 & $1.05-1.69$ & 0.041 \\
\hline Baseline 6MWT & 0.83 & $0.31-0.96$ & 0.043 \\
\hline End-of-study $6 \mathrm{MWT}$ & 0.98 & 0.87-1.09 & NS \\
\hline Baseline PMG & 0.98 & $0.86-1.43$ & NS \\
\hline End-of-study PMG & 1.12 & $0.89-1.54$ & NS \\
\hline Baseline MMG & 1.14 & $0.98-1.23$ & NS \\
\hline End-of-study MMG & 1.03 & 0.97-1.09 & NS \\
\hline Baseline MVA & 1.09 & $0.89-1.10$ & NS \\
\hline End-of-study MVA & 1.01 & $0.99-1.02$ & NS \\
\hline Baseline ANP & 1.10 & $0.93-1.22$ & NS \\
\hline End-of-study ANP & 0.98 & $0.87-1.04$ & NS \\
\hline Baseline BNP & 1.11 & $0.96-1.23$ & NS \\
\hline End-of-study BNP & 1.07 & $0.95-1.13$ & NS \\
\hline
\end{tabular}

PCWP - pulmonary capillary wedge pressure, PAP - pulmonary artery pressure, 6MWT - 6-minute walk test, PMG - peak mitral gradient, MMG - mean mitral gradient, MVA - mitral valve area, ANP - A-type natriuretic peptide, BNP B-type natriuretic peptide.

with lower mitral valve area (MVA) $(r=-0.393, p=0.023)$ and lower $\mathrm{CO}(r=-0.239, p=0.022)$. On the other hand, pre-procedural BNP concentration correlated positively with PCWP $(r=0.382, p=0.021), \operatorname{LAP}(r=0.327, p=0.023)$, PAP $(r=0.622, p=0.011), M M G(r=0.344, p=0.023)$ and negatively with $\mathrm{CO}(r=-0.329, p=0.025)$ and MVA $(r=-0.278, p=0.013)$. Needless to say, pre-procedural ANP and BNP correlated positively with each other $(r=$ $0.845, p<0.001)$.

The end-of-study ANP concentration correlated with the following parameters measured at the end of fol-

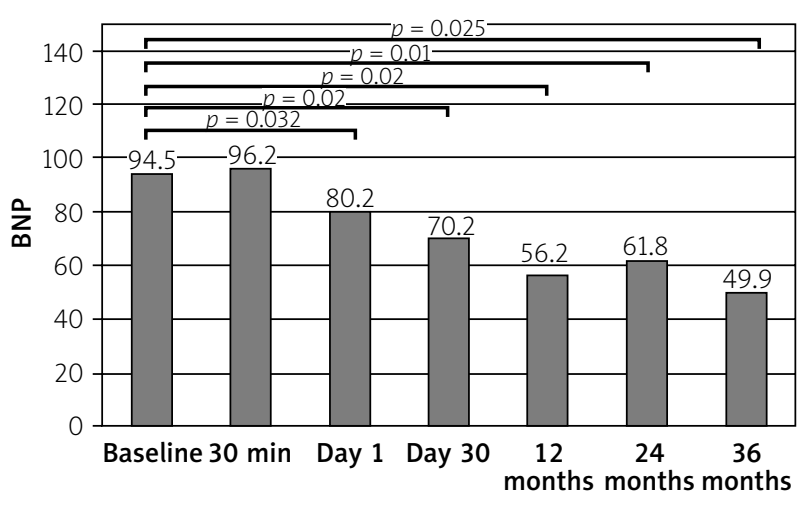

Figure 2. Changes in BNP concentrations during follow-up

low-up: MGM $(r=0.368, p=0.024)$, MVA $(r=-0.368$, $p=0.024)$. On the other hand, end-of-study BNP concentration correlated with final MGM $(r=0.493, p=0.019)$, PMG $(r=0.421, p=0.029)$ and MVA $(r=-0.318, p=$ 0.018).

The percentage change in concentration of ANP and BNP did not correlate either with percentage change in mitral area orifice, LAP, or transmitral gradients. The only factor which correlated with the percentage change in BNP concentration was change in pulmonary artery pressure $(r=0.392, p=0.023)$.

\section{Prognostic analysis}

Clinical, echocardiographic, hemodynamic, functional and neurohormonal variables were entered into a regression analysis model to search for predictors of endpoints during the follow-up period in the study group.

In univariate analysis 4 parameters were associated with endpoint occurrence. These were baseline PAP, baseline PCWP, baseline NYHA and increase in 6MWT (Table IV).

In multivariate analysis, the only factor associated with endpoint occurrence was baseline NYHA class $(\mathrm{HR}=1.52,95 \% \mathrm{Cl}: 1.3-1.91, p=0.022)$.

\section{Discussion}

Our study is the first to prospectively analyze the long-term neurohormonal follow-up in a relatively large population of patients with mitral stenosis treated with PBMV. Our main findings were:

1. Patients with MS had significantly higher concentrations of both ANP and BNP at baseline as compared with healthy subjects.

2. BNP concentration after PBMV was lower than at baseline and continued to fall during follow-up.

3. Higher baseline levels of both ANP and BNP were associated with more severe mitral stenosis in echocardiography (lower MVA, higher PMG and MGM) and higher PCWP and lower CO on catheterization. 
4. Baseline NYHA class was found to be associated with outcomes after the procedure.

We found that patients with MS had significantly higher levels of both ANP and BNP at baseline in comparison with healthy subjects, which is in agreement with many previous studies [25, 32, 33]. Moreover, it has been demonstrated that higher ANP and BNP levels were associated with the severity of mitral stenosis according to echocardiography (lower MVA, higher PMG and MGM) and hemodynamics (higher PCWP and lower CO). Previous studies also reported the association between increased BNP levels and elevated NYHA class, higher PAP as well as more severe mitral stenosis according to echocardiography [34, 35].

The main advantage of our study is a prospective analysis of long-term neurohormonal follow-up in a relatively large population of patients with mitral stenosis undergoing PBMV. So far only Sharma et al. have identified BNP as a predictor of treadmill exercise capacity in similar group of patients [36]. To date the prognostic value of neurohormone concentrations was well established only in patients with congestive heart failure of different origin [37-40]. In our study neurohormones did not prove their prognostic value in patients with MS. Of note, despite improvement of clinical status and the positive correlation between the levels of two studied neuropeptides, we did not observe a continuous ANP decrease. That may be a surprise taking into account that previous studies found that ANP level decreased significantly after PBMV and correlated with the parameters of mitral stenosis [36]. It can be speculated whether the large number of patients with atrial fibrillation in this study group compared to patients with heart failure of other origin might have an impact on the prognostic value on ANP. However, we found no differences either in neurohormonal or in clinical profile or in prognosis between patients with sinus rhythm and atrial fibrillation. Inoue et al. concluded that the presence of atrial fibrillation might have influenced the levels of neurohormones [41]. In the case of smaller investigated populations of patients with MS and atrial arrhythmias, patients with AF had higher levels of neurohormones and higher NYHA class as compared to subjects with sinus rhythm [42]. We assumed that a larger study population and a relatively high percentage of patients who had a change in heart rhythm during the study might explain the lack of differences between those subgroups.

Distinguishing between asymptomatic and mildly symptomatic patients is especially difficult in MS due to the long latent period between the onset of rheumatic fever and the development of significant valvular obstruction. During this time patients may gradually adapt their lifestyle, thereby masking early symptoms. Measurement of ANP and BNP might be helpful in differentiation of truly symptomatic patients from subjects inap- propriately considered symptomatic, due to non-cardiac dyspnea resulting in physical deconditioning. Therefore, the ANP and BNP levels can be used as a complementary tool for the clinical and echocardiographic evaluation of patients with MS. On the other hand, based on the very good correlation between reduction of BNP and PAP, BNP can serve as a marker of success of the immediate result of PBMV. Moreover, either ANP or BNP correlates with the function of the mitral valve after the valvuloplasty; therefore the measurement of both neurohormones during follow-up might be helpful in identification of subjects with restenosis.

Moreover, BNP levels correlated positively with PAP. The development of pulmonary hypertension in patients with MS is believed to be the main cause of their exercise limitation [43]. Although in some studies BNP level did not correlate with any hemodynamic parameters [27], those studies were based on relatively small patient populations and did not take into consideration the invasive treatment. Some authors reported a lack of serial measurement of ANP and BNP as a limitation of their research [44]. Our findings based on long-term follow-up confirm their suspicions that releasing the narrowed valve and decreasing PAP can lead to a further fall of BNP concentration.

\section{Limitation of the study}

We used BNP, instead of its metabolite NT-proBNP, which has a longer half-life than BNP. However, since an excellent correlation between those two peptides was established, we presume that our results are reliable.

\section{Conclusions}

To sum up, patients with MS had increased levels of both BNP and ANP. The decrease of BNP can serve as a valid marker reflecting changes in PAP after PBMV. Finally, only baseline NYHA class was found to be associated with outcomes after the procedure.

\section{Conflict of interest}

The authors declare no conflict of interest.

\section{References}

1. Becker AE. Acquired heart valve pathology. An update for the millennium. Herz 1998; 23: 415-9.

2. Adams DH. Degenerative mitral valve disease: introduction. Semin Thorac Cardiovasc Surg 2007; 19: 8.

3. Veinot JP. Pathology of inflammatory native valvular heart disease. Cardiovasc Pathol 2006; 15: 243-51.

4. Vahanian A, lung B, Himbert D, Nataf P. Changing demographics of valvular heart disease and impact on surgical and transcatheter valve therapies. Int J Cardiovasc Imaging 2011; 27: 1115-22.

5. Carapetis JR, Steer AC, Mulholland EK, Weber M. The global burden of group A streptococcal diseases. Lancet Infect Dis 2005; 11: 685-94. 
6. Wood P. An appreciation of mitral stenosis. I. Clinical features. $\mathrm{Br}$ Med J 1954; 1: 1051-63.

7. Zakkar M, Amirak E, Chan KM, Punjabi PP. Rheumatic mitral valve disease: current surgical status. Progress Cardiovasc Dis 2009; 51: 478-81.

8. lung B. Mitral stenosis still a concern in heart valve diseases. Archf Cardiovasc Dis 2008; 101: 597-9.

9. Goswami KC, Rao MB, Dev V, Shrivastava S. Juvenile tricuspid stenosis and rheumatic tricuspid valve disease: an echocardiographic study. Int J Cardiol 1999; 72: 83-6.

10. Chandrashekhar Y, Westaby S, Narula J. Mitral stenosis. Lancet 2009; 374: 1271-83.

11. Singh M, Malhotra P, Thakur JS. Rheumatic heart disease in developing countries. Lancet 1997; 349: 1700.

12. Marijon E, Mirabel M, Celermajer DS, Jouven X. Rheumatic heart disease. Lancet 2012; 379: 953-64.

13. Mittal SR, Khanna S, Mathur D. Rheumatic mitral and tricuspid valve disease. Int J Cardiol 1997; 59: 317-9.

14. American College of Cardiology/American Heart Association Task Force on Practice G, Society of Cardiovascular A, Society for Cardiovascular Angiography and I, Society of Thoracic S, Bonow RO, Carabello BA, et al. ACC/AHA 2006 guidelines for the management of patients with valvular heart disease: a report of the American College of Cardiology/ American Heart Association Task Force on Practice Guidelines (writing committee to revise the 1998 Guidelines for the Management of Patients With Valvular Heart Disease): developed in collaboration with the Society of Cardiovascular Anesthesiologists: endorsed by the Society for Cardiovascular Angiography and Interventions and the Society of Thoracic Surgeons. Circulation 2006; 114: e84-231.

15. Cannan CR, Nishimura RA, Reeder GS, et al. Echocardiographic assessment of commissural calcium: a simple predictor of outcome after percutaneous mitral balloon valvotomy. J Am Coll Cardiol 1997; 29: 175-80.

16. Goswami KC, Bahl VK, Talwar KK, et al. Percutaneous balloon mitral valvuloplasty using the Inoue balloon: analysis of echocardiographic and other variables related to immediate outcome. Int J Cardiol 1999; 68: 261-8.

17. Yates LA, Harper RW, Peverill RE, Smolich JJ. Balloon mitral valvuloplasty at Monash Medical Centre: follow up of 201 procedures over an 11-year period. Heart Lung Circulation 2001; 10: 83-5.

18. Kothari SS, Ramakrishnan S, Juneja R, Yadav R. Percutaneous transvenous mitral commissurotomy in patients with severe mitral stenosis and acute rheumatic fever. Pediatr Cardiol 2006; 27: 347-50.

19. Mukoyama M, Nakao K, Morii N, et al. Brain natriuretic peptide as a novel cardiac hormone in humans: evidence for an exquisite dual natriuretic peptide system, atrial natriuteric peptide and brain natriuretic peptide. J Clin Invest 1991; 87: 1402-12.

20. Yoshimura M, Yasue H, Morita E, et al. Hemodynamic, renal, and hormaonal responses to brain natriuretic peptide infusion in patients with congestive heart failure. Circulation 1991; 84: 1581-8.

21. Richards AM, Nicholls MG, Yandle TG, et al. Plasma N-terminal pro-brain natriuretic peptide and adrenomedullin: new neurohormonal predictors of left ventricular function and prognosis after myocardial infarction. Circulation 1998; 97: 1921-9.

22. Matsumoto A, Hirata $\mathrm{Y}$, Momomura S, et al. Effects of exercise on plasma level of brain natriuretic peptide in congestive heart failure with and without left ventricular dysfunction. Am Heart J 1995; 129: 139-45.
23. Levin ER, Gardner DG, Samson WK. Natriuretic peptides. N Engl J Med 1998; 339: 321-8.

24. Eryol NK, Dogan A, Ozdogru I, et al. The relationship between the level of plasma B-type natriuretic peptide and mitral stenosis. Int J Cardiovasc Imaging 2007; 23: 569-74.

25. Iltumur K, Karabulut A, Yokus B, et al. N-terminal proBNP plasma levels correlate with severity of mitral stenosis. J Heart Valve Dis 2005; 14: 735-41.

26. Selcuk MT, Selcuk H, Maden O, et al. The effect of percutaneous balloon mitral valvuloplasty on $\mathrm{N}$-terminal-pro B-type natriuretic peptide plasma levels in mitral stenosis. Int Heart J 2007; 48: 579-90.

27. Nakamura M, Kawata $\mathrm{Y}$, Yoshida $\mathrm{H}$, et al. Relationship between plasma atrial and brain natriuretic peptide concentration and hemodynamic parameters during percutaneous transveneous mitral valvulotomy in patients with mitral stenosis. Am Heart J 1992; 124: 1283-8.

28. Schiller NB, Shah PM, Crawford M, et al. American Society of Echocardiography Committee on standards, subcommittee on quantification of two-dimensional echocardiograms. Recommendations for quantitation of left ventricle by two-dimensional echocardiography. J Am Soc Echocardiogr 1989; 2: 358-67.

29. Kircher BJ, Himmelman RB, Schiller NB. Noninvasive estimation of right atrial pressure from the inspiratory collapse of inferior vena cava. Am J Cardiol 1990; 66: 493-6.

30. Martin RP, Rakowski H, Kleiman JH, et al. Reliability and reproducibility of two dimensional echocardiography measurement of stenotic mitral valve orifice area. Am J Cardiol 1979; 43: 560-8.

31. Inoue K, Owaki T, Nakamura T, et al. Clinical application of transvenous mitral commissurotomy by a new balloon catheter. J Thorac Cardiovasc Surg 1984; 87: 394-402.

32. Arat-O-zkan A, Kaya A, Yig Z, et al. N-Terminal pro-BNP levels correlate with symptoms and echocardiographic findings in patients with MS. Echocardiography 2005; 22: 473-8.

33. Eryol NK, Dogan A, Ozdogru I, et al. The relationship between the level of plasma B-type natriuretic peptide and mitral stenosis. Int J Cardiovasc Imaging 2007; 23: 569-74.

34. Razzolini R, leoni I, Cafiero F, et al. Neurohormones in MS before and after percutaneous balloon mitral valvotomy. J Heart Valve Dis 2002; 11: 185-90.

35. Selcuk MT, Selcuk H, Maden O, et al. The effect of percutaneous balloon mitral valvuloplasty on N-terminal-pro B-type natriuretic peptide plasma levels in mitral stenosis. Int Heart J 2007; 48: 579-90.

36. Sharma V, Stewart RA, Zeng I, et al. Comparison of atrial and brain natriuretic peptide for the assessment of mitral stenosis. Heart Lung Circ 2011; 20: 517-24.

37. Dickstein K, Cohen-Solal A, Filippatos G, et al. ESC guidelines for the diagnosis and treatment of acute and chronic heart failure 2008: the Task Force for the diagnosis and treatment of acute and chronic heart failure 2008 of the European Society of Cardiology. Developed in collaboration with the Heart Failure Association of the ESC (HFA) and endorsed by the European Society of Intensive Care Medicine (ESICM). Eur J Heart Fail 2008; 10: 933-89.

38. Langenickel T, Pagel I, Hohnel K, et al. Differential regulation of cardiac ANP and BNP mRNA in different stages of experimental heart failure. Am J Physiol Heart Circ Physiol 2000; 278: H1500-6.

39. Matsumoto A, Hirata Y, Momomura S, et al. Effects of exercise on plasma level of brain natriuretic peptide in congestive heart 
failure with and without left ventricular dysfunction. Am Heart J 1995; 129: 139-45.

40. Sullivan DR, West $M$, Jeremy R. Utility of brain natriuretic peptide (BNP) measurement in cardiovascular disease. Heart Lung Circulation 2005; 14: 78-84.

41. Inoue S, Murakami Y, Sano K. Atrium as a source of BNP in patients with atrial fibrillation. J Card Fail 2000; 6: 92-6.

42. Golbawy Z, Ucarb O, Yukselb AG, et al. Plasma brain natriuretic peptide levels in patients with rheumatic heart disease. Eur J Heart Failure 2004; 6: 757-60.

43. Nagaya N, Nishikimi T, Okano Y, et al. Plasma brain natriuretic peptide levels increase in proportion to the extent of right ventricular dysfunction in pulmonary hypertension. J Am Coll Cardiol 1998; 31: 202-8.

44. Goetze JP, Friis-Hansen L, Rehfeld JF, et al. Atrial secretion of B-type natriuretic peptide. Eur Heart J 2006; 27: 1648-50. 